\title{
Pharmaceutical nanotechnology: from the bench to the market
}

\author{
Zaed M. Mazayen ${ }^{1}$, Amira M. Ghoneim ${ }^{1 *}$, Rasha S. Elbatanony ${ }^{1}$, Emad B. Basalious ${ }^{2}$ and Ehab R. Bendas ${ }^{1}$
}

\begin{abstract}
Background: Nanotechnology is considered a new and rapidly emerging area in the pharmaceutical and medicinal field. Nanoparticles, as drug delivery systems, impart several advantages concerning improved efficacy as well as reduced adverse drug reactions.

Main body: Different types of nanosystems have been fabricated including carbon nanotubes, paramagnetic nanoparticles, dendrimers, nanoemulsions, etc. Physicochemical properties of the starting materials and the selected method of preparation play a significant aspect in determining the shape and characteristics of the developed nanoparticles. Dispersion of preformed polymers, coacervation, polymerization, nano-spray drying and supercritical fluid technology are among the most extensively used techniques for the preparation of nanocarriers. Particle size, surface charge, surface hydrophobicity and drug release are the main factors affecting nanoparticles physical stability and biological performance of the incorporated drug. In clinical practice, many nanodrugs have been used for both diagnostic and therapeutic applications and are being investigated for various indications in clinical trials. Nanoparticles are used for the cure of kidney diseases, tuberculosis, skin conditions, Alzheimer's disease, different types of cancer as well as preparation of COVID-19 vaccines.
\end{abstract}

Conclusion: In this review, we will confer the advantages, types, methods of preparation, characterization methods and some of the applications of nano-systems.

Keywords: Nanotechnology, Delivery systems, Fabrication, Characterization, Applications

\section{Background}

Nanotechnology is the molecular-scale fabrication of various functioning systems. These systems have special physical, electrical, and optical characteristics that make them appealing in a variety of domains, ranging from materials science to biology [1]. Nanomedicine is one of the most well-known nanotechnology research fields. It uses nanotechnology to develop highly targeted medicinal interventions for disease detection, prevention, and treatment [2]. Over the last few decades, there has been a spike in nanomedicine research, which is currently being turned into commercialization activities around

\footnotetext{
*Correspondence: amohsen@fue.edu.eg

1 Faculty of Pharmacy, Department of Pharmaceutical Technology, Future University in Egypt, Cairo 11835, Egypt

Full list of author information is available at the end of the article
}

the world, culminating in the marketing of numerous products. Drug delivery systems now dominate nanomedicine, with revenues accounting for over $75 \%$ of total sales [3]. Nanoparticles have a diameter of $10-1000 \mathrm{~nm}$. Entrapped, encapsulated, dissolved, or linked to the nanoparticle matrix is the active pharmaceutical ingredient (API) [4]. Nanoparticles can be made by altering the method of fabrication. Nanoparticles have been proven to be useful as drug delivery vehicles. Many uses for nanoparticulate drug delivery systems exist, including gene therapy, cancer therapy, AIDS therapy, and radiation. It can also be used to transport proteins, antibiotics, and vaccinations, as well as serve as vesicles to cross the blood-brain [5]. The major aims of nanoparticle design as a delivery system are to control particle size, surface properties, and drug delivery and API release so as to ensure site-targeted drug activity at an appropriate 
therapeutic rate and dosing regimen. In this review, we will discuss the advantages of nanoparticles as drug delivery systems, different types of nanosystems and their applications. We will also explain different methods used in the fabrication and characterization of nanoparticles. Examples of marketed nanoparticles products will be provided as well.

\section{Main text}

\section{Benefits of utilizing nanoparticles as a drug delivery} system

The benefits of employing nanoparticles as drug vehicles are because of two key characteristics: their tiny size and the use of biodegradable materials in the majority of cases $[6,7]$. The effectiveness of most medication delivery methods is found to be largely reliant on particle size. Drug nanoparticles exhibit increased solubility and superior bioavailability which is a result of their small particle size and large surface area [8]. Additionally, their ability to cross the blood brain barrier, entering pulmonary system, endothelium of tumors and absorption through tight junctions of skin endothelial cells, give them added value. The nano-range size of these particles, in general, allows for effective absorption by various cell types as well as selective drug accumulation in the target locations $[9,10]$.

Nanoparticles also have the benefit of being more adequate for intravenous administration than conventional microparticles. The smallest body capillaries have a diameter of 5-6 m. To make sure that particles do not cause embolism, the size of particles dispersed in the circulation should be substantially less than $5 \mathrm{~m}$ [11]. Using both natural and synthetic biodegradable polymers for nanoparticle preparation give them the advantages of targeted drug delivery, improve bioavailability and achieve sustained release behavior of medications from a single dose at the target site over a prolonged period of time; by adaptation of the system, endogenous enzymes can be prevented from destroying the drug [12].

Furthermore, typical oral or injectable medicines now accessible for use are not necessarily provided in the most suitable formulation. As a result, goods containing proteins or nucleic acids will require more creative carrier systems (nanoparticles) to improve their efficacy and avoid any instability [13].

\section{Types of pharmaceutical nanosystems Carbon nanotubes}

Carbon nanotubes were first found in 1991 [14]. They are tubular carbon-based structures. These tubes are made up of cylinders of graphite sheets that are sealed at one or both ends by bucky balls and range in length from 1 to $100 \mathrm{~nm}$. Single-walled nanotubes (SWNTs) and multiwalled nanotubes (MWNTs) are two designs that have recently gained popularity (MWNTs). C60-fullerenes are also found in typical configurations. They come in a variety of graphite cylinder configurations and are known for being cage-like and hollow (nanotubes and fullerenes). They are suitable for drug encapsulation because of their surface features and size, and they have crucial physical qualities. The DNA helix has a diameter of half the size of SWNTs. MWNTs, on the other hand, have diameters that range from a few nanometers to tens of nanometers, depending on how many walls they have in their structure [15]. Chemical vapor deposition, combustion procedures and electric arc discharge are the most common methods for producing fullerenes and carbon nanotubes. The strength and stability of these structures are used to characterize them so that they can be used as trustworthy drug transporters. Endocytosis or insertion across the cell membrane is how nanotubes enter cells. The structures of fullerenes were able exhibit tissue targeting and intracellular targeting of mitochondria. Additionally, it was found that that they show both antioxidant and antimicrobial activity [16].

\section{Quantum dots}

Quantum dots (QDs) are made up of semi-conducting structures that are $2-10 \mathrm{~nm}$ in size. They are nanocrystals with an inorganic semi-conductor core (CdSe) and an organic shell coated with zinc sulphide to increase optical qualities, and they are designed to glow when under the influence of light. The addition of a cap improves the solubility of QDs in aqueous buffers [17]. The particle's radius spans from 2 to $10 \mathrm{~nm}$. Several qualities have been attributed to the long-term tracking of intracellular processes, bio-imaging in vitro, and real-time monitoring. Narrow emission, strong photo-stability, broad UV excitation, and brilliant fluorescence are some of these properties [18]. Cell labelling, biomolecule detection and biological performance, DNA hybridization, immunoassays, and the creation of non-viral vectors for gene therapy, carriers for cancer treatment, and transport vehicles for biological and non-biological agents are some of the diagnostic and therapeutic applications of QDs [19].

\section{Nanoshells}

Nanoshells are altered models for drug targeting, with a silica core and outer layer of metal [20]. Nowadays, much attention was gained by these nanoshells. The characteristics of these particles can be changed by adjusting the ratio between the core and the shell. It is now feasible to formulate these nanostructures in targeted physical properties, like size and morphology. Because all of the materials cannot be formulated in the desired morphologies, nanoshells are used to create new systems with 
a variety of morphologies. Particles of specific shapes could be covered with thin shell to achieve appropriate morphology. These shells have the advantage of being inexpensive since precious materials can be added to low-cost cores. As a result, precious material is needed in smaller quantities during synthesizing nanoshells [21]. Nanoshells targeting can be obtained by immunological techniques; an example for this targeting strategy is the gold nanoshells which were occupied with antibodies moieties on its outer gold surface for enhancement of the targeting power toward the cancer cell [22]. Nanoshells occupy different functions in varied areas like chemically stabilizing colloids, improving luminescence features and drug [23].

\section{Nanobubbles}

Nanobubbles are bubble-shaped particles formed at the nanoscale at the interface of lipophilic surfaces in liquids. When heated to body temperature, they mix to form microbubbles, which are stable at room temperature. They arise in supersaturated solutions as a result of gas nucleation at the hydrophobic surface, resulting in air gas trapping. There are 4 types of these nanoparticles; plasmonic, bulk, oscillating and interfacial nanobubbles. Drugs for cancer treatment were successfully loaded into these particles, they were able to target tumor tissues and increase the tumor cells uptake with the influence of ultrasound exposure [24, 25].

\section{Paramagnetic nanoparticles}

Magnetic nanoparticles are small particles with a diameter of fewer than $100 \mathrm{~nm}$ that can be controlled by a magnetic field. Magnetic elements are used to make these particle materials. The magnetic sensitivity of these nanoparticles is used to classify them. Magnetic susceptibility of paramagnetic nanoparticles is higher than that of typical contrast forms. These nanoparticles are utilized for diagnostic and treatment strategies. Paramagnetic nanoparticles targeting is effective for identification of specific organs [26].

\section{Liposomes}

Liposomes are synthetics particles made from amphiphilic phospholipids that self-assemble. They are made up of spherical double layered vesicles that surround an aqueous core domain that can range in size from $50 \mathrm{~nm}$ to several micrometres depending on the kind. General biocompatibility and biodegradability are appealing biological characteristics of liposomes. Liposomes are the most often utilized nanosystems as drug vehicles in clinical trials. They can be utilized to decrease medication clearance as well as reduce systemic effects and toxicity [27]. For the transfer of DNA, siRNA, proteins, and cancer treatments, nanoscale modified liposomes have good pharmacokinetic characteristics.

Low loading capacity, rapid drug release and the lack of adjustable drug release patterns are all limitations of liposomes [28]. Drugs are also discharged into the extracellular fluid because liposomes are unable to penetrate cells [29]. Following oral or parenteral administration, stability and structural integrity against a hostile bioenvironment can be achieved by surface modification [30]. Drugs can be incorporated in the water phase of liposomes using an ammonium sulphate gradient to counteract the rapid release of the drug from liposomes. This will allow for consistent drug trapping and minimal drug loss throughout circulation [31]. Liposomes have also been coupled to antibodies to deliver medication to particular targets [32].

\section{Niosomes}

Niosomes are a type of molecular cluster formed in an aqueous phase by the self-assembly of non-ionic surfactants. Niosomes have a unique architecture that allows them to function as a new delivery method that can accommodate both lipophobic and lipophilic agents [33]. Niosomes consist of non-ionic surfactants, they are characterized by their non-toxicity, high stability and they are considered to be a replacement to liposomes. In vivo, niosomes act like liposomes; the entrapped drug's circulation is extended, and organ distribution and metabolic stability are changed. Characteristics of niosomes rely upon the bilayer, besides the preparation technique. It is proved that the entrapment volume during formulation decreases as a result of intercalation of cholesterol in the bilayers, and this leads to a reduction in the entrapment efficiency [34]. Present conclusions for the adoption of niosomes in the delivery of drugs are with a broad extent in entrapment of potent drugs [35], anticancer [36] and anti-viral medications [34].

\section{Dendrimers}

Dendrimers are a special category of polymers, characterized by being multi-branched, with a controllable size and shape. The size of these dendrimers is determined by the degree of branching, which may be regulated. Additionally, spherical branching within dendrimers creates voids that can be benefited for drug entrapment and delivery. The free ends of dendrimers, on the other hand, can be changed for conjugation to other molecules [37]. These nanostructures are advanced in terms of surface functionalization and stability, making them unique drug delivery possibilities. There are three main fundamental areas in terms of construction: core, branches, and surface. These networks help in the delivery of bioactives like medicines, genes, and vaccinations to specific tissues. 
Solubilization, gene therapy [38], dendrimer-based drug delivery [39], immunoassay, and MRI contrast agent are only a few of the uses for dendrimers.

\section{Polymeric micelles}

Polymeric micelles are a type of micelle made up of lipophilic and lipophobic monomer units in a block copolymer. They are made up of a center of lipophilic blocks that is stabilized by a corona of lipophilic polymeric chains. Corona-forming PEG blocks are utilized, and the length of a lipophilic center-forming block is similar to that of a hydrophilic block [40]. As a medication carrier, a micellar system has various advantages over conventional systems. Using micelle-forming surfactants to promote drug solubility improves the solubility of a weakly water-soluble medicine. They also increase the permeability of medications across physiological barriers, which improves their bioavailability. As a result, alterations in drug biodistribution occur. They help reduce negative side effects of critical medications. As a result of their reduced size and lipophilic shell, polymeric micelles remain in the blood for prolonged time after intravenous delivery, reducing their uptake by the reticulo-endothelial system. Micelles can also be made target specific by chemically attaching a targeting component to their surface. Because it is in a micellar form, the medication is effectively shielded from possible deterioration due to biological surroundings [41]. Because it is in a micellar form, it will find its path to the target organ or tissue.

\section{Polymeric nanoparticles}

Polymeric nanoparticles (PNPs) are mostly biodegradable and biocompatible; therefore, researchers are drawn to biodegradable PNPs as a drug-delivery system [42, 43]. PNPs are subdivided into vesicular systems (nanocapsules) and matrix systems (nanospheres). Advance modification of natural polymers was recently explored by researchers which comprises synthetic polyesters. One of the most familiar natural polymers is chitosan. Many polymers reduce toxic issues with the artificial polymers [44]. Natural PNPs prevailed over traditional delivery systems, due to their higher efficiency and effectiveness. Nevertheless, they have some drawbacks like poor reproducibility, degradation problems and potential antigenicity. The encapsulated drug's release behavior is controlled by the manufacturing technique. PNPs are potential intracellular and site-targeting systems.

\section{Nanocapsules}

Nanocapsules and nanospheres vary in that the former are carriers where the drug is contained in a core enclosed by a polymeric membrane, while the latter are structures where the drug is disseminated through the polymeric matrix [45]. PNPs can be thought of as a matrix in which the drug is equally distributed. Across or inside the polymeric matrix, the medication might be dissolved, entrapped, or encapsulated. PNPs are an excellent alternative for cancer therapy and other applications due to their capacity to customize medication delivery [46].

\section{Solid lipid nanoparticles}

Solid lipid NPs (SLN) were produced as a substitute to emulsions, liposomes and PNPs as a colloidal drug delivery system in a controlled manner [46]. SLNs are prepared from solid lipids and stabilized by surfactant(s). SLN offers several benefits for drug delivery over other particle carriers, including superior tolerability, biodegradability, high bioavailability via the ocular route, and a targeted impact on the brain $[47,48]$. The research of SLN has exploded in recent years, notably with the highpressure homogenization technique. SLN has been produced and studied for a variety of applications. The small size of SLN allowed them to become injected intravenously and used for site-targeting of drugs.

\section{Nanoemulsions}

Nanoemulsions and self-emulsified drug delivery systems (SEDDS) have gained a lot of interest in recent years as a way to increase the bioavailability of medicines of low aqueous solubility. Nanoemulsions are non-homogenous systems made up of immiscible liquids where one is disseminated as droplets in the other [49]. When integrated into aqueous phases under mild mixing, SNEDDS are isotropic mixes of oil, surfactant, co-surfactant, and drug that produce oil-in-water $(\mathrm{o} / \mathrm{w})$ nanoemulsions [50]. By a variety of processes these systems improve the oral bioavailability of weakly water soluble medicines. Furthermore, the small size of the droplets reduces the surface tension between the oil droplets and the aqueous medium of the gastrointestinal tract, allowing for more uniform and widespread drug distribution in the gut [51].

\section{Fabrication of nanoparticles}

The physicochemical characteristics of the polymer as well as the selected drug determine the suitable method for the preparation. Nanoparticles mainly have been synthesized by different methods including dispersion of pre-formulated polymers, co-acervation of hydrophilic polymers and polymerization of monomers [52]. Other techniques have been mentioned in the literature for production of nanoparticles including supercritical fluid technology [53] and particle replication in non-wetting templates [54]. 


\section{Dispersion of preformed polymers}

This method relies on the fabrication of biodegradable nanoparticles through the dispersion of biodegradable polymers [55-57]. Dispersion of preformed polymers can be utilized in different ways:

Solvent evaporation method One of the most commonly used procedures for the production of nanoparticles is solvent evaporation. Emulsification of the polymer solution in an aqueous phase is the initial stage, followed by evaporation of the polymer solvent, which results in polymer precipitation as nanospheres. This technique is dependent on the polymer's solubility as well as the hydrophobicity of the organic solvent. To produce an oil in water $(\mathrm{o} / \mathrm{w})$ emulsion, the drug-polymer combination is emulsified in an aqueous solution including a surfactant or emulsifying agent. The organic solvent is then evaporated by continuous stirring or by reducing the pressure, once the stable emulsion is formed. Several factors were found to affect the size range of nanoparticles. Among these factors are the concentrations and type of both the stabilizer and the polymer, and the homogenizer speed [58]. Ultrasonication or high-speed homogenization may be used to fabricate small particle size. Ultracentrifugation is used to collect nanoparticles, then they are washed using distilled water to remove stabilizer residue or any free drug. Nanoparticles are further lyophilized for storage. There are two modifications for this method; solvent evaporation method and high pressure emulsification [59]. The latter method involves preparation of an emulsion which was homogenized under high pressure followed by removal of organic solvent by steering. Many drugs activity were improved and enhanced by preparation as nano-formulation using solvent evaporation method, examples include improved skin penetration of ibuprofen [60] and Betulinic acid nanoparticles as Visceral Leishmaniasis alternative treatment [61].

Spontaneous emulsification This method works with both lipophilic and lipophobic medicines. A multiple $\mathrm{w} / \mathrm{o} / \mathrm{w}$ emulsion with the medication dispersed in the internal aqueous phase is required for lipophobic drugs [62].

Double emulsion and evaporation method Many evaporation-based techniques have the disadvantage of poor hydrophilic drug entrapment. To load the lipophobic drug, the double emulsion approach is employed, by adding drug solutions to an organic solution, containing the polymer, while continuously stirring to produce a w/o emulsion. The generated emulsion is then continuously incorporated into the second aqueous phase. To make the $\mathrm{w} / \mathrm{o} / \mathrm{w}$ emulsion, keep swirling. The solvent is then evapo- rated, and the nanoparticles may be separated using highspeed centrifugation. Before lyophilization, the produced nanoparticles must be cleaned. The quantity of integrated hydrophilic drug, the stabilizer concentration, the polymer concentration, and the volume of aqueous phase all have a role in the characterization of nanoparticles in this procedure [63]. Some examples for drugs nano-formulations prepared by double emulsion technique include Rose Bengal for breast cancer treatment [64] and oleuropein with improved stability [65].

Salting out method Salting-out effect depends mainly on the separation of a water miscible solvent from aqueous solution. Both the medication and the polymer are dissolved in a vehicle in the first phase, which is then emulsified into an aqueous gel with the salting out agent and a colloidal stabilizer. Salting out agents (electrolytes, as well as non-electrolytes) and colloidal stabilizers have been used [66]. This technique produces an oil/water emulsion, which is subsequently diluted with enough water to enhance solvent diffusion in the aqueous phase, allowing for the formation of nanospheres. Salting out technique is used for the synthesis of ethyl cellulose, PLA and Poly (methacrylic) acids nanospheres. This method has the advantage of minimizing the stress on the protein included in encapsulants formation and resulted in high efficiency and is easily scaled up [67].

Emulsions-diffusion method Another way to make nanoparticles is to use this technique. To establish the first thermodynamic equilibrium of both liquids, the encapsulating polymer is dissolved in a partly water-miscible solvent (such as propylene carbonate or benzyl alcohol) and saturated with water. The polymer-water saturated solvent phase is then emulsified in an aqueous solution containing a stabilizer, causing solvent diffusion to the exterior phase and the production of nanospheres or nanocapsules, depending on the oil-to-polymer ratio. In the last step, the solvent is removed by evaporation or filtration, depending on its boiling point. This technique has several benefits, such as high encapsulation efficiencies, no need for homogenization, high batch-to-batch reproducibility, scale up easily, simplicity, and narrow size distribution [44]. This technique was used for preparation of estrogen-loaded PLGA-nanoparticles [58] and synthesis of poly lactic acid [68].

Solvent displacement method In this process, pre-formulated polymer is precipitated in an organic solution, while the organic solvent is dispersed in the aqueous solution [69]. Surfactants can be added to aid the diffusion of organic solvent [70]. After completely dissolving, the solution is injected into an aqueous solution containing 
a stabilizer while being constantly stirred. Fast solvent diffusion causes nanoparticles to develop spontaneously. The solvent is then removed from the suspensions at low pressure after this phase. The ratio of the organic phase to the aqueous phase determines particle size. It is well understood that raising the mixing rate of the two phases reduces particle size and drug entrapment [69]. This technique is not suitable for encapsulating of hydrophilic drugs but limited for those with poor solubility with an advantage of the ease of scaling up for industrial production [6]. Regulating the polymer concentration in the organic phase has proven to be effective in the formulation of smaller sized nanospheres. Nonetheless, size range is confined to minimum range of the polymer to drug ratio [44]. Examples for preparations were done by this technique include preparation of Boldine-loaded PLGA nanoparticles [71], Functionalized polyaniline nanoparticles [72], N-Acetylcysteine loaded in PLGA nanoparticles [73] and Non-isocyanate polyurethane nanoparticles [74].

\section{Coacervation or ionic gelation method}

Ionic gelation could be utilized for the production of hydrophilic polymer based nanoparticles [75]. This technique is first reported by Calvo and coworkers in 1997 $[76,77]$. It depends on the great electrostatic attraction between positively charged amino group of chitosan as well as negatively charged tripolyphosphate where two different aqueous phases were prepared, one for polymer and the other is for polyanion sodium tripolyphosphate to formulate coacervates that have a size in nanometer range [78]. Other examples used this technique involve the preparation of advanced controlled released chitosan nanoparticles with improved properties of less aggregation tendency using tripolyphosphate-beta-cyclodextrin complex [79], levofloxacin loaded polymeric nanoparticles [80], and encapsulation of anthocyanins antioxidant for improved stability [81].

\section{Polymerization method}

This method is done in aqueous solution by polymerization of monomers to form nanoparticles. Drug is incorporated by two different methods during polymerization process (either by diffusion in the polymerization medium or by adsorption onto the nanoparticles after complete polymerization) [82]. Ultracentrifugation can be utilized to separate nanoparticle suspension from different stabilizers and surfactants that were used during polymerization, followed by the re-dispersion of the nanoparticles in an isotonic medium free from surfactants. The desired size of nanoparticles can be obtained by optimizing concentration of the surfactants and stabilizers. There are many applications and researches were achieved using polymerization technique include synthesis of super hydrophobic cotton fabrics [83, 84] and fabrication of nonporous polyimide silsesquioxane nanostructure as soft dielectric materials [85].

\section{Nano spray drying}

Spray drying is a fast, simple, reproducible, and scalable drying technology, which allows mild temperature condition suitable for heat-sensitive biopharmaceutical compounds. Spray drying, in comparison to other drying methods, is a continuous process that converts different liquids to solid particles while allowing for size, distribution, shape, porosity, density, and chemical composition adjustments. Spray drying equipment are commercially accessible, and the cost of manufacturing is cheaper than other drying methods such as freeze drying [86]. Spray drying involves four steps: (1) heating the drying gas, (2) droplet production, (3) droplet drying, and (4) particle collecting. Nano spray drying enables the generation of smaller particle sizes than conventional spray dryers that improves bioavailability and release of bioactive components and drugs. Drug-loaded nanoparticles provide several benefits, including a greater surface-to-volume ratio, a better rate of cell penetration, increased stability, and the capacity to pinpoint release [87].

\section{Supercritical fluid technology}

The previously mentioned conventional methods utilize organic solvents that are dangerous to the environment and the physiological systems. Supercritical fluid technology has been utilized as an alternative to manufacture biodegradable micro- and nanoparticles since supercritical fluids are ecologically friendly [88]. Even though environmentally friendly and suitability for mass production, supercritical fluid technology needs specific expensive equipment. Supercritical fluids are fluids, when are at a temperature higher than its critical temperature, still remain homogenous, regardless of pressure. Supercritical $\mathrm{CO}_{2}\left(\mathrm{SC}-\mathrm{CO}_{2}\right)$ is the most broadly applied supercritical fluid due to its moderate critical conditions, non-flammability, considerable price and safety [89].

\section{Applications of nanoparticles \\ Nanoparticles in the treatment of kidney diseases}

In urology and nephrology, nanoparticles are utilized to treat renal disorders. Ferumoxytol has been included into nanoparticles for the treatment of patients with chronic kidney disease or end-stage renal disease who do not produce enough erythropoietin [90]. Due to the onset of numerous diseases from this area, PEGylated gold nanoparticles can also target the mesangium-contractile cells that make up the central stalk of the glomerulus of the kidney. Rhein, an anthraquinone derivative used to treat diabetic nephropathy, had its distribution and therapeutic 
Table 1 Examples of FDA-approved nanomedicines

\begin{tabular}{|c|c|c|c|c|}
\hline Trade name & Material description & Advantages & Indications & Approval year \\
\hline Estrasorb $^{\mathrm{TM}}$ & Micellar Estradiol & Controlled delivery of the drug & Menopausal therapy & 2003 \\
\hline Marqibo ${ }^{\circledR}$ & Liposomal Vincristine & \multirow{2}{*}{$\begin{array}{l}\text { Increased delivery to tumor tissue; } \\
\text { decreased systemic toxicity resulting } \\
\text { from side-effects }\end{array}$} & Acute lymphoblastic leukemia & 2012 \\
\hline Onivyde ${ }^{\circledR}$ & Liposomal Irinotecan & & Pancreatic cancer & 2015 \\
\hline $\begin{array}{l}\text { BNT162b2 vac- } \\
\text { cine (developed } \\
\text { by BioNTech and } \\
\text { Pfizer) }\end{array}$ & $\begin{array}{l}\text { Nucleoside modified mRNA encod- } \\
\text { ing the viral spike glycoprotein of } \\
\text { SARS-CoV-2, encapsulated in lipid } \\
\text { nanoparticles }\end{array}$ & $\begin{array}{l}\text { Protection of the non-replicating } \\
\text { RNA from degradation and allow it } \\
\text { to be delivered into host cells after } \\
\text { intramuscular injection }\end{array}$ & Prevention of coronavirus disease & 2020 \\
\hline $\begin{array}{l}\text { mRNA-1273 vac- } \\
\text { cine (developed } \\
\text { by Moderna) }\end{array}$ & $\begin{array}{l}\text { Lipid nanoparticle-encapsulated } \\
\text { mRNA-based vaccine, which encodes } \\
\text { the spike protein (S protein) of SARS- } \\
\text { CoV-2 }\end{array}$ & $\begin{array}{l}\text { Lipid nanoparticles are playing a key } \\
\text { role in protecting and transporting } \\
\text { the mRNA effectively to the right } \\
\text { place in cells }\end{array}$ & Prevention of coronavirus disease & 2020 \\
\hline
\end{tabular}

impact increased thanks to nanoparticle technology. Triblock amphiphilic was used to make Rhein nanoparticles. Rhein nanoparticles were synthesized using triblock amphiphilic polymers, namely polyethylene glycol-copolycaprolactone-co-polyethylenimine. The size of nanoparticles prepared was about $75 \mathrm{~nm}$ which is optimum for kidney-targeted drug delivery. The results demonstrated that distribution to kidney as well as therapeutic effects of the drug were improved [83].

Nanoparticles for treatment of tuberculosis by chemotherapy The improved efficacy of the anti-TB medicines loaded nanoparticles was due to their changed release behavior following oral administration. Rifampin, isoniazid, and pyrazinamide, three major medicines were co-incorporated in PLG-nanoparticles. These medications' therapeutic concentrations in tissues were kept for 10 days, but free drugs only lasted 1 day in the plasma after injection $[91,92]$.

\section{Nanoparticles topical drug delivery for skin diseases}

PNPs are the most extensively used nanoparticles for medication administration on the skin [93]. PNPs made from chitosan and alginate are used to treat acne, and as compared to benzoyl peroxide alone, they showed improved antibacterial efficacy against Propionibacterium acnes $[94,95]$. In addition to polymeric nanoparticles, electro-spun fibres mats have a high surface area-to-volume ratio, which helps with the effective dispersion of both hydrophobic and hydrophilic medications and making them ideal for topical drug administration [93, 96]. Liposomes, solid lipid nanoparticles (SLN), and nanostructured lipid carriers (NLC) all cling to the surface of the skin. Liposomes, solid lipid nanoparticles (SLN), and nanostructured lipid carriers (NLC) bind to the skin's surface, allowing lipid exchange between the stratum corneum's outermost layers and the carrier for better medication penetration. Inflammatory skin illnesses including psoriasis and atopic eczema were treated with lipid-based carrier systems containing glucocorticoids and T-cell suppressing drugs like cyclosporin and tacrolimus. Surface modified SLNs containing retinyl palmitate improved the drug's cutaneous dispersion when compared to neutral SLNs, according to Jeon et al. [97]. Recent research has revealed that incorporating retinol into Compritol-based SLN make the drug released more rapidly as compared to conventional carrier [98-100].

\section{Drug targeting to infectious diseases by nanoparticles}

The physical and chemical properties of nanoparticles are being used as a tool to treat a variety of infectious disorders. The use of a therapeutic medicine loaded on a nano-vector has boosted the efficacy of the drug against infectious disorders. The polyethylene glycol-modified carbon nanotubes are the most common type of nonviral delivery system due to their enhanced pharmacokinetic and toxic characteristics. These are efficient carriers of bioactive molecules in the delivery of specific drugs for the treatment of infectious illnesses [101, 102].

\section{Applications of nanoparticles in treating Alzheimer's disease} Nanoparticle-mediated medication delivery is one of the newest approaches for increasing CNS penetration for the diagnosis and treatment of neurodegenerative diseases like Alzheimer's disease. PNPs are promising candidates among the various nanocarriers used because, in addition to being able to open the tight junctions of the Blood Brain Barrier, they effectively conceal the membrane barrier confining characterizations of the drug molecule, prolonging drug release and protecting drugs against enzymatic hydrolysis [103, 104]. 


\section{Nanoparticles containing different anticancer agents}

Nano-oncology is a new discipline of medicine that makes use of nanoparticles to treat cancer. The use of nanoparticles as an effective medication improves cancer cell targeting and overcomes cancer tissue multidrug resistance [105]. PLGA is a widely used polymer for making nanoparticles, and it has been utilized to make drug-loaded nanoparticles for cancer therapy due to its biocompatibility and long-term drug release. PLGA has been used to successfully manufacture anticancer drugs such as doxorubicin, 5-fluorouracil, paclitaxel, and dexamethasone. The FDA authorized Nutropin Depot, a microsphere version of Somatropin-PLGA nanoparticle, in 1999 as a once-time treatment. Nutropin Depot, a microsphere version of Somatropin-PLGA nanoparticle, was approved by the FDA in 1999 as a once-per-month alternative to daily HGH injections [106]. Doxorubicin is an anticancer medication that is primarily used to treat a variety of cancers. This feature limits its therapeutic potential because it is a very toxic substance that affects not just tumour tissue but also the heart and kidney. The creation of doxorubicin in liposomes, on the other hand, resulted in an FDA-approved nanomedical drug delivery system [107]. This new liposomal formulation lowered doxorubicin transport to the heart and kidney while increasing doxorubicin accumulation [108].

\section{Nanoparticles in vaccination against COVID-19}

During the year 2020 and now, all scientists and researchers are concentrating their efforts on creating remedies to combat the worldwide epidemic of the COVID-19 virus. In the year 2021, the importance of nanoparticle technology in the development of therapeutic formulations for the diagnosis, treatment, and promotion of long-term human immunity against COVID-19 was highlighted [109]. The backbone in succession and acceleration of the time required for creation of COVID-19 nanoparticle-based vaccines (CNPBV) was the recorded genome structure from Corona viruses and the pre-knowledge of the sequence of the protein laying the virus surface [110]. Spikes are present.

The presence of spike proteins on the outer surface of the COVID-19 virus, which have a high connecting tendency toward nano-formulations and a high binding tendency toward host cell receptors, was employed as a key characteristic in the development of CNPBV [111]. A promising vaccine based on nanotechnology was approved by the food and drug administration (FDA) and proved its big value in prophylaxis against COVID-19 virus with a high percentage of $90 \%$ on the vaccinated population among various vaccines produced with moderate efficacy to fight and limit the spread of the COVID-19 pandemic around the world. Pfizer-BioNTech
(BNT162b2 vaccine) and Moderna vaccine (mRNA1273 vaccine) are two of these vaccinations [112]. PfizerBioNTech (BNT162b2 vaccine) and Moderna vaccine (mRNA-1273 vaccine) are two vaccines that rely on mRNA to encode the COVID-19 virus's spike glycoprotein $(S)$ and then incorporating the modified mRNA (which encodes the virus glycolprotein) into lipid-based nanoparticles [113]. The encapsulated modified mRNA then aids in the transport of the protein antigen (spike protein) to immune cells, stimulating $\mathrm{T}$ cell activity and inducing antibody immunological responses within the human body [114].

\section{FDA approved nanomedicines}

In the last few decades, different nano-pharmaceuticals have been approved for clinical use from the food and drug administration (FDA). Among approved nanodrugs, liposomal, polymeric and micelles were represented and administered using oral, intravenous and transdermal routes. Table 1 [115] shows representative examples of FDA approved nano-medicines.

\section{Conclusions}

Nanotechnology is a promising science with variety of advantages and applications in the medical field. It overcame the problems associated with conventional drug delivery systems and took the chance to accomplishment in production of COVID-19 vaccines based on lipid nanoparticle with higher efficiency over the others conventional vaccines. More efforts are needed to increase the number of FDA approved nano-drugs and further studies must be done to understand the development of the unique properties of these magical particles.

\section{Abbreviations \\ API: Active pharmaceutical ingredient; SWNTs: Single-walled nanotubes; MWNTs: Multiwalled nanotubes; QDs: Quantum dots; PNPs: Polymeric nano- particles; SLN: Solid lipid NPs; SEDDS: Self-emulsified drug delivery systems; o/w: Oil-in-water; NLC: Nanostructured lipid carriers; CNPBV: Nanoparticle- based vaccines. \\ Acknowledgements \\ Not applicable. \\ Authors' contributions \\ All authors contributed equally in the conception, writing, collecting data, revising and editing. All authors read and approved the final manuscript. \\ Funding \\ No funding was received by any of the authors.}

Availability of data and materials

Not applicable. 


\section{Declarations}

Ethics approval and consent to participate

Not applicable.

\section{Consent for publication}

All authors have approved the final article and consented to publication.

\section{Competing interests}

All authors declare that they have no competing interest.

\section{Author details}

${ }^{1}$ Faculty of Pharmacy, Department of Pharmaceutical Technology, Future University in Egypt, Cairo 11835, Egypt. ${ }^{2}$ Faculty of Pharmacy, Department of Pharmaceutics and Industrial Pharmacy, Cairo University, Cairo, Egypt.

\section{Received: 23 November 2021 Accepted: 1 January 2022}

\section{Published online: 15 January 2022}

\section{References}

1. Bamrungsap S, Zhao Z, Chen T, Wang L, Li C, Fu T, Tan W (2012) Nanotechnology in therapeutics: a focus on nanoparticles as a drug delivery system. Nanomedicine 7(8):1253-1271. https://doi.org/10.2217/nnm. 12.87

2. Lobatto ME, Fuster V, Fayad ZA, Mulder WJ (2011) Perspectives and opportunities for nanomedicine in the management of atherosclerosis. Nat Rev Drug Discov 10(11):835-852. https://doi.org/10.1038/nrd3578

3. Wagner V, Dullaart A, Bock AK, Zweck A (2006) The emerging nanomedicine landscape. Nat Biotechnol 24(10):1211-1217. https://doi.org/ 10.1038/nbt1006-1211 (PMID: 17033654

4. Mohanraj V, Chen Y (2006) Nanoparticles-a review. Trop J Pharm Res 5(1):561-573

5. Tiwari G, Tiwari R, Sriwastawa B, Bhati L, Pandey S, Pandey P, Bannerjee SK (2012) Drug delivery systems: an updated review. Int J Pharm Investig 2:2-11. https://doi.org/10.4103/2230-973X.96920.PMID:23071954; PMCID:PMC346514

6. Amoabediny G, Haghiralsadat F, Naderinezhad S, Helder MN, Akhoundi Kharanaghi E, Mohammadnejad Arough J, Zandieh-Doulabi B (2018) Overview of preparation methods of polymeric andlipid-based (niosome, solid lipid, liposome) nanoparticles: a comprehensive review. Int J Polym Mater Polym Biomater 67(6):383-400

7. Wilson DR, Sen R, Sunshine JC, Pardoll DM, Green JJ, Kim YJ (2018) Biodegradable STING agonist nanoparticles for enhanced cancer immunotherapy. Nanomed Nanotechnol Biol Med 14(2):237-246. https://doi. org/10.1016/j.nano.2017.10.013

8. Rizvi SA, Saleh AM (2018) Applications ofnanoparticle systems in drug delivery technology. Saudi Pharm J 26(1):64-70

9. Kohane DS (2007) Microparticles and nanoparticles for drug delivery. Biotechnol Bioeng 96(2):203-209

10. Panyam J, Labhasetwar V (2003) Biodegradable nanoparticles for drug and gene delivery to cells and tissue. Adv Drug Deliv Rev 55(3):329-347

11. Singh R, Lillard JW Jr (2009) Nanoparticle-based targeted drug delivery. Exp Mol Pathol 86(3):215-223

12. Zhang J, Saltzman M (2013) Engineering biodegradable nanoparticles for drug and gene delivery. Chem Eng Prog 109(3):25-30

13. Vo TN, Kasper FK, Mikos AG (2012) Strategies for controlled delivery of growth factors and cells for bone regeneration. Adv Drug Deliv Rev 64(12):1292-1309

14. lijima S (1991) Helical microtubules of graphitic carbon. Nature 354(6348):56-58

15. Reilly RM (2007) Carbon nanotubes: potentialbenefits and risks of nanotechnology in nuclear medicine. J Nucl Med 48(7):1039-1042

16. Saad ZH, Jahan R, Bagul U (2012) Nanopharmaceuticals: a new perspective of drug delivery system. Asian J Biomed Pharm Sci 2(14):11-20

17. Iga AM, Robertson JH, Winslet MC, Seifalian AM (2008) Clinical potential of quantum dots. BioMed Res Int 2007(10):76087. https://doi.org/10. $1155 / 2007 / 76087$
18. Amiot $C L$, Shuping Xu, Liang S, Pan L, Zhao JX (2008) Near-infrared fluorescent materials for sensing of biological targets. Sensors 8(5):30823105. https://doi.org/10.3390/s8053082

19. Bailey RE, Smith AM, Nie S (2004) Quantum dots in biology and medicine. Phys E 25(1):1-12

20. West JL, Halas NJ (2000) Applications of nanotechnology to biotechnology: commentary. Curr Opin Biotechnol 11(2):215-217

21. Kalele SW, Gosavi S, Urbn J, Kulkarni S (2006) Nanoshell particles: synthesis, properties and applications. Curr Sci 91(8):1038-1052

22. Loo C, Lowery A, Halas N, West J, Drezek R (2005) Immunotargeted nanoshells for integrated cancer imaging and therapy. Nano Lett 5(4):709-711. https://doi.org/10.1021/nl050127s

23. Kherlopian AR, Song T, Duan Q, Neimark MA, Po MJ, Gohagan JK, Laine AF (2008) A review of imaging techniques for systems biology. BMC Syst Biol 2(1):74. https://doi.org/10.1186/1752-0509-2-74

24. Gao Z, Kennedy AM, Christensen DA, Rapoport NY (2008) Drug-loaded nano/microbubbles for combining ultrasonography and targeted chemotherapy. Ultrasonics 48(4):260-270. https://doi.org/10.1016/j. ultras.2007.11.002

25. Klibanov AL (2006) Microbubble contrast agents: targeted ultrasound imaging and ultrasound-assisted drug-delivery applications. Investig Radiol 41(3):354-362. https://doi.org/10.1097/01.rli.0000199292.88189

26. Cuenca AG, Jiang H, Hochwald SN, Delano M, Cance WG, Grobmyer SR (2006) Emerging implications of nanotechnology on cancer diagnostics and therapeutics. Cancer 107(3):459-466. https://doi.org/10.1002/cncr. 22035

27. Torchilin VP (2005) Recent advances with liposomes as pharmaceutical carriers. Nat Rev Drug Discov 4(2):145-160. https://doi.org/10.1038/ nrd1632

28. Nekkanti $\bigvee$, Kalepu S (2015) Recent advances in liposomal drug delivery: a review. Pharm Nanotechnol 3(1):35-55

29. Laverman P, Carstens MG, Boerman OC, Dams ET, Oyen WJ, van Rooijen $\mathrm{N}$, Corstens FH, Storm G (2001) Factors affecting the accelerated blood clearance of polyethyleneglycol-liposomes upon repeated injection. J Pharmacol Exp Ther 298(2):607-612

30. Lee SM, Chen H, Dettmer CM, O'Halloran TV, Nguyen ST (2007) Polymercaged lipsomes: a pH-responsive delivery system with high stability. J Am Chem Soc 129(49):15096-15097. https://doi.org/10.1021/ja070748i

31. Gabizon AA, Shmeeda H, Zalipsky S (2006) Pros and cons of the liposome platform in cancer drug targeting. J Liposome Res 16(3):175-183

32. Cho K, Wang X, Nie S, Chen ZG, Shin DM (2008) Therapeutic nanoparticles for drug delivery in cancer. Clin Cancer Res 14(5):1310-1316. https://doi.org/10.1158/1078-0432.CCR-07-1441

33. Moghassemi S, Hadjizadeh A (2014) Nano-niosomes as nanoscale drug delivery systems: an illustrated review. J Control Release 185:22-36

34. Kazi KM, Mandal AS, Biswas N, Guha A, Chatterjee S, Behera M, Kuotsu K (2010) Niosome: a future of targeted drug delivery systems. J Adv Pharm Technol Res 1(4):374-380. https://doi.org/10.4103/0110-5558. 76435

35. MalikT, Chauhan G, Rath G, Kesarkar RN, Chowdhary AS, Goyal AK (2018) Efaverinz and nano-gold-loaded mannosylated niosomes: a host cell-targeted topical HIV-1 prophylaxis via thermogel system. Artif Cells Nanomed Biotechnol 46(sup1):79-90. https://doi.org/10.1080/21691 401.2017.1414054

36. Shah HS, Khalid F, Bashir S et al (2019) Emulsion-templated synthesis and in vitro characterizations of niosomes for improved therapeutic potential of hydrophobic anti-cancer drug: tamoxifen. J Nanopart Res 21(2):1-10. https://doi.org/10.1007/s11051-019-4464-y

37. Moghimi SM, Hunter AC, Murray JC (2005) Nanomedicine: current status and future prospects. FASEB J 19(3):311-330

38. Pedziwiatr-Werbicka E, Serchenya T, Shcharbin D, Terekhova M, Prokhira E, Dzmitruk V, Shyrochyna I, Sviridov O, Peña-González CE, Gómez R, Sánchez-Nieves J, Javier de la Mata F, Bryszewska M (2017) Dendronization of gold nanoparticles decreases their effect on human alpha1-microglobulin. Int J Biol Macromol. https://doi.org/10.1016/j.ijbiomac. 2017.11.004

39. Huang D, Wu D (2018) Biodegradable dendrimers for drug delivery. Mater Sci Eng 90:713-727

40. Torchilin V (2004) Targeted polymeric micelles for delivery of poorly soluble drugs. Cell Mol Life Sci CMLS 61(19-20):2549-2559 
41. Sahoo S, Misra SR, Parveen S (2017) Nanoparticles: a boon to drug delivery, therapeutics, diagnostics and imaging. Nanomedicine 8(2):147-166. https://doi.org/10.1016/j.nano.2011.05.016

42. Karlsson J, Vaughan HJ, Green JJ (2018) Biodegradable polymeric nanoparticles for therapeutic cancer treatments. Annu Rev Chem Biomol Eng 9:105-127

43. Sahoo SK, Labhasetwar V (2003) Nanotech approaches to drug delivery and imaging. Drug Discov Today 8(24):1112-1120

44. Bhatia S (2016) Nanoparticles types, classification, characterization, fabrication methods and drug delivery applications. In: Bhatia S (ed) Natural polymer drug delivery systems: nanoparticles, plants, and algae. Springer International Publishing, Cham, Switzerland, pp 33-93

45. Mora-Huertas CE, Fessi H, Elaissari A (2010) Polymer-based nanocapsules for drug delivery. Int J Pharm 385(1-2):113-142

46. Kayser O, Lemke A, Hernandez-Trejo N (2005) The impact of nanobiotechnology on the development of new drug delivery systems. Curr Pharm Biotechnol 6(1):3-5

47. Cavalli R, Gasco MR, Chetoni P, Burgalassi S, Saettone MF (2002) Solid lipid nanoparticles (SLN) as ocular delivery system for tobramycin. Int J Pharm 238(1-2):241-245. https://doi.org/10.1016/s0378-5173(02) 00080-7

48. Yang SC, Lu LF, Cai Y, Zhu JB, Liang BW, Yang CZ (1999) Body distribution in mice of intravenously injected camptothecin solid lipid nanoparticles and targeting effect on brain. J Control Release 59(3):299-307. https:// doi.org/10.1016/s0168-3659(99)00007-3

49. Singh KK, Vingkar SK (2008) Formulation, antimalarial activity and biodistribution of oral lipid nanoemulsion of primaquine. Int J Pharm 347(1-2):136-143

50. Nazzal S, Smalyukh II, Lavrentovich OD, Khan MA (2002) Preparation and in vitro characterization of a eutectic based semisolid self-nanoemulsified drug delivery system (SNEDDS) of ubiquinone: mechanism and progress of emulsion formation. Int J Pharm 235(1-2):247-265

51. Cai Z, Wang Y, Zhu LJ, Liu ZQ (2010) Nanocarriers: a general strategy for enhancement of oral bioavailability of poorly absorbed or pre-systemically metabolized drugs. Curr Drug Metab 11(2):197-207. https://doi. org/10.2174/138920010791110836

52. Kumar B, Jalodia K, Kumar P, Gautam HK (2017) Recent advances in nanoparticlemediated drug delivery. J Drug Deliv Sci Technol 41:260-268

53. Reverchon E, Adami R (2006) Nanomaterials and supercritical fluids. J Supercrit Fluids 37(1):1-22

54. Rolland JP, Maynor BW, Euliss LE, Exner AE, Denison GM, DeSimone JM (2005) Direct fabrication and harvesting of monodisperse, shape-specific nanobiomaterials. J Am Chem Soc 127(28):10096-10100. https:// doi.org/10.1021/ja051977c

55. Kompella U, Bandi N, Ayalasomayajula S (2001) Poly (lactic acid) nanoparticles for sustained release of budesonide. Drug Deliv Technol 1:1-7

56. Kumar MR, Bakowsky U, Lehr C (2004) Preparation and characterization of cationic PLGA nanospheres as DNA carriers. Biomaterials 25(10):1771-1777

57. Li YP, Pei YY, Zhou ZH, Zhang XY, Gu ZH, Ding J, Zhou JJ, Gao XJ (2001) PEGylated polycyanoacrylate nanoparticles as tumor necrosis factor-a carriers. J Control Release 71(3):287-296. https://doi.org/10.1016/s01683659(01)00235-8

58. Kwon HY, Lee JY, Choi SW, Jang Y, Kim JH (2001) Preparation of PLGA nanoparticles containing estrogen byemulsification-diffusion method. Colloids Surf A 182(1-3):123-130. https://doi.org/10.1016/S09277757(00)00825-6

59. Jaiswal J, Gupta SK, Kreuter J (2004) Preparation of biodegradable cyclosporine nanoparticles by high-pressure emulsification-solvent evaporation process. J Control Release 96(1):169-178

60. Deng Y, Yang F, Zhao X, Wang L, Wu W, Zu C, Wu M (2018) Improving the skin penetration and antifebrile activity of ibuprofen by preparing nanoparticles using emulsion solvent evaporation method. Eur J Pharm Sci 114:293-302. https://doi.org/10.1016/j.ejps.2017.12.024

61. Halder A, Shukla D, Das S, Roy P, Mukherjee A, Saha B (2018) Lactoferrinmodified betulinic acid-loaded PLGA nanoparticles are strong antileishmanials. Cytokine 110:412-415. https://doi.org/10.1016/j.cyto.2018. 05.010

62. Shinde NC, Keskar NJ, Argade PD (2012) Nanoparticles: advances in drug delivery systems. Res J Pharm Biol Chem Sci 3:922-929
63. Ubrich N, Bouillot P, Pellerin C, Hoffman M, Maincent P (2004) Preparation and characterization of propranolol hydrochloride nanoparticles: a comparative study. J Control Release 97(2):291-300

64. Loya-Castro MF, Sánchez-Mejía M, Sánchez-Ramírez DR, DomínguezRíos R, Escareño N, Oceguera-Basurto PE, Fiqueroa-Ochoa ÉB, Quintero A, Del Toro-Arreola A, Topete A, Daneri-Navarro A (2018) Preparation of PLGA/Rose Bengal colloidal particles by double emulsion and layer-bylayer for breast cancer treatment. J Colloid Interface Sci 518:122-129. https://doi.org/10.1016/j.jcis.2018.02.013

65. Gharehbeglou P, Jafari SM, Homayouni A, Hamishekar H, Mirzaei H (2019) Fabrication of double W1/O/W2 nano-emulsions loaded with oleuropein in the internal phase (W1) and evaluation of their release rate. Food Hydrocoll 89(44-55):991-1003. https://doi.org/10.1016/j. foodhyd.2018.10.020

66. Mura S, Nicolas J, Couvreur P (2013) Stimuli-responsive nanocarriers for drug delivery. Nat Mater 12:991-1003

67. Jung T, Kamm W, Breitenbach A, Kaiserling E, Xiao JX, Kissel T (2000) Biodegradable nanoparticles for oral delivery of peptides: is there a role for polymers to affect mucosal uptake? Eur J Pharm Biopharm 50:147-160. https://doi.org/10.1016/s0939-6411(00)00084-9

68. Hong JS, Srivastava D, Lee I (2018) Fabrication of poly (lactic acid) nano-and microparticles using a nanomixer via nanoprecipitation or emulsion diffusion. J Appl Polym Sci 135(18):46199

69. Piñón-Segundo E, Ganem-Quintanar A, Rafael Garibay-Bermúdez J, Juan Escobar-Chávez J, López-Cervantes M, Quintanar-Guerrero D (2006) Preparation of nanoparticles by solvent displacement using a novel recirculation system. Pharm Dev Technol 11(4):493-501. https:// doi.org/10.1080/10837450600940824

70. Jahangiri A, Barghi L (2018) Polymeric nanoparticles: review of synthesismethods and applications in drug delivery. J Adv Chem Pharm Mater 1(2):38-47

71. Mondal J, Patra M, Panigrahi AK, Khuda-Bukhsh AR (2018) Boldineloaded PLGA nanoparticles have improved efficiency of drug carriage and protective potential against Cisplatin-induced toxicity. J Ayurveda Integr Med 1(1):24-36. https://doi.org/10.1016/j.jaim.2017.11.002

72. Abel SB, Yslas El, Rivarola CR, Barbero CA (2018) Synthesis of polyaniline (PANI) and functionalized polyaniline (F-PANI) nanoparticles with controlled size by solvent displacement method. Application in fluorescence detection and bacteria killing by photothermal effect. Nanotechnology 29(12):125604. https://doi.org/10.1088/1361-6528/ aaa99a

73. Lancheros R, Guerrero CA, Godoy-Silva RD (2018) Improvement of $\mathrm{N}$-acetylcysteine loaded in PLGA nanoparticles by nanoprecipitation method. J Nanotechnol 2018:11. https://doi.org/10.1155/2018/3620373

74. Querette T, Fleury E, Sintes-Zydowicz N (2019) Non-isocyanate polyurethane nanoparticles prepared by nanoprecipitation. Eur Polym J 114:434-445

75. Sundar S, Kundu J, Kundu SC (2010) Biopolymeric nanoparticles. Sci Technol Adv Mater 11(1):014104-014104

76. Calvo P, Remuñán-López C, Vila-Jato JL, Alonso MJ (1997) Novel hydrophilic chitosan-polyethylene oxide nanoparticles as protein carriers. J Appl Polym Sci 63(1):125-132

77. Divya K, Jisha M (2018) Chitosan nanoparticles preparation and applications. Environ Chem Lett 16(1):101-112

78. Qi L, Xu Z, Jiang X, Hu C, Zou X (2004) Preparation and antibacterial activity of chitosan nanoparticles. Carbohydr Res 339(16):2693-2700. https://doi.org/10.1016/j.carres.2004.09.007

79. Pant A, Negi JS (2018) Novel controlled ionic gelation strategy for chitosan nanoparticles preparation using TPP- $\beta-C D$ inclusion complex. Eur J Pharm Sci 112:180-185

80. López-López M, Fernández-Delgado A, Moyá ML, Blanco-Arévalo D, Carrera C, de la Haba RR, Ventosa A, Bernal E, López-Cornejo P (2019) Optimized preparation of levofloxacin loaded polymeric nanoparticles. Pharmaceutics 11(2):57. https://doi.org/10.3390/pharmaceutics11 020057

81. de Moura SCSR, Berling CL, Germer SPM, Alvim ID, Hubinger MD (2018) Encapsulating anthocyanins from Hibiscus sabdariffa L. calyces by ionic gelation: pigment stability duringstorage of microparticles. Food Chem 241:317-327. https://doi.org/10.1016/j.foodchem.2017.08.095

82. Boudad H, Legrand P, Lebas G, Cheron M, Duchêne D, Ponchel G (2001) Combined hydroxypropyl- $\beta$-cyclodextrin and poly (alkylcyanoacrylate) 
nanoparticles intended for oral administration of saquinavir. Int J Pharm 218(1-2):113-124. https://doi.org/10.1016/s0378-5173(01)00622-6

83. Chen D, Han S, Zhu Y, Hu F, Wei Y, Wang G (2018) Kidney-targeted drug delivery via rhein-loaded polyethyleneglycol-co-polycaprolactone-copolyethylenimine nanoparticles for diabetic nephropathy therapy. Int J Nanomed 13:3507-3527. https://doi.org/10.2147/IJN.S166445

84. Jiang B, Chen Z, Sun Y, Yang H, Zhang H, Dou H, Zhang L (2018) Fabrication of superhydrophobic cotton fabrics using crosslinking polymerization method. Appl Surf Sci 441:554-563

85. Hawkins M, Saha S, Ravindran E, Rathnayake H (2019) A sol-gel polymerization method for creating nanoporous polyimide silsesquioxane nanostructures as soft dielectric materials. J Polym Sci Part A Polym Chem 57(4):562-571

86. Arpagaus C, John Ph, Collenberg A, Rütti D (2017) Chapter 10: Nanocapsules formation by nano spray drying. In: Jafari SM (ed) Nanoencapsulation technologies for the food and neutraceutical industries. Academic Press, Elsevier, London, pp 346-401

87. Arpagaus C, Collenberg A, Rütti D, Assadpour E, Jafari SM (2018) Nano spray drying for encapsulation of pharmaceuticals. Int J Pharm 546(1-2):194-214. https://doi.org/10.1016/j.ijpharm.2018.05.037

88. Jung J, Perrut M (2001) Particle design using supercritical fluids: literature and patent survey. J Supercrit Fluids 20(3):179-219

89. Sun YP, Meziani MJ, Pathak P, Qu L (2005) Polymeric nanoparticles from rapid expansion of supercritical fluid solution. Chem A Eur J 1(5):13661373. https://doi.org/10.1002/chem.200400422

90. Brede C, Labhasetwar V (2013) Applications of nanoparticles in the detection and treatment of kidney diseases. Adv Chronic Kidney Dis 20(6):454-465

91. Gelperina S, Kisich K, Iseman MD, Heifets L (2005) The potential advantages of nanoparticle drug delivery systems in chemotherapy of tuberculosis. Am J Respir Crit Care Med 172(12):1487-1490. https://doi. org/10.1164/rccm.200504-613PP

92. Pandey R, Zahoor A, Sharma S, Khuller GK (2003) Nanoparticle encapsulated antitubercular drugs as a potential oral drug delivery system against murine tuberculosis. Tuberculosis 83(6):373-378. https://doi. org/10.1016/j.tube.2003.07.001

93. Goyal R, Macri LK, Kaplan HM, Kohn J (2016) Nanoparticles and nanofibers for topical drug delivery. J Control Release 240:77-92. https://doi. org/10.1016/j.jconrel.2015.10.049

94. Boddupalli BM, Mohammed ZN, Nath RA, Banji D (2010) Mucoadhesive drug delivery system: an overview. J Adv Pharm Technol Res 1(4):381-387. https://doi.org/10.4103/0110-5558.76436

95. Friedman AJ, Phan J, Schairer DO, Champer J, Qin M, Pirouz A, BlecherPaz K, Oren A, Liu PT, Modlin RL, Kim J (2013) Antimicrobial and antiinflammatory activity of chitosan-alginate nanoparticles: a targeted therapy for cutaneous pathogens. J Investig Dermatol 133(5):12311239. https://doi.org/10.1038/jid.2012.399

96. Verreck G, Chun I, Rosenblatt J, Peeters J, Dijck AV, Mensch J, Noppe M, Brewster ME (2003) Incorporation of drugs in an amorphous state into electrospun nanofibers composed of a water-insoluble, nonbiodegradable polymer. J Control Release 92(3):349-360. https://doi.org/10. 1016/s0168-3659(03)00342-0

97. Jeon HS, Seo JE, Kim MS, Kang MH, Oh DH, Jeon SO, Jeong SH, Choi YW, Lee S (2013) A retinyl palmitate-loaded solid lipid nanoparticle system: effect of surface modification with dicetyl phosphate on skin permeation in vitro and anti-wrinkle effect in vivo. Int J Pharm 452(1-2):311320. https://doi.org/10.1016/j.ijpharm.2013.05.023

98. Jenning V, Schäfer-Korting M, Gohla S (2000) Vitamin A-loaded solid lipid nanoparticles for topical use: drug release properties. J Control Release 66(2-3):115-126

99. Schäfer-Korting M, Mehnert W, Korting HC (2007) Lipid nanoparticles for improved topical application of drugs for skin diseases. Adv Drug Deliv Rev 59(6):427-443

100. Wissing S, Kayser O, Müller R (2004) Solid lipid nanoparticles for parenteral drug delivery. Adv Drug Deliv Rev 56(9):1257-1272

101. Bottini M, Rosato N, Bottini N (2011) PEG-modified carbon nanotubes in biomedicine: current status and challenges ahead. Biomacromol 12(10):3381-3393

102. Sundar S, Kumar Prajapati V (2012) Drug targeting to infectious diseases by nanoparticles surface functionalized with special biomolecules. Curr Med Chem 19(19):3196-3202
103. Roney C et al (2005) Targeted nanoparticles for drug delivery through the blood-brain barrier for Alzheimer's disease. J Control Release 108(2-3):193-214

104. Sahni JK, Doggui S, Ali J, Baboota S, Dao L, Ramassamy C (2011) Neurotherapeutic applications of nanoparticles in Alzheimer's disease. J Control Release 152(2):208-231. https://doi.org/10.1016/j.jconrel.2010. 11.033

105. Hashemi Goradel N, Ghiyami-Hour F, Jahangiri S, Negahdari B, Sahebkar A, Masoudifar A, Mirzaei H (2018) Nanoparticles as new tools for inhibition of cancer angiogenesis. J Cell Physiol 233(4):2902-2910. https:// doi.org/10.1002/jcp.26029

106. Acharya S, Sahoo SK (2011) PLGA nanoparticles containing various anticancer agents and tumour delivery by EPR effect. Adv Drug Deliv Rev 63(3):170-183

107. Abraham SA, Waterhouse DN, Mayer LD, Cullis PR, Madden TD, Bally MB (2005) The liposomal formulation of doxorubicin. Methods Enzymol 391:71-97. https://doi.org/10.1016/S0076-6879(05)91004-5

108. Safra T, Muggia F, Jeffers S, Tsao-Wei DD, Groshen S, Lyass O, Henderson R, Berry G, Gabizon A (2000) Pegylated liposomal doxorubicin (doxil): reduced clinical cardiotoxicity in patients reaching or exceeding cumulative doses of 500 mg/m2. Ann Oncol 11(8):1029-1033. https://doi. org/10.1023/a:1008365716693

109. Yang D (2021) Application of nanotechnology in the COVID-19 pandemic. Int J Nanomed 16:623-649. https://doi.org/10.2147/IJN.S296383

110. Vahedifard F, Chakravarthy K (2021) Nanomedicine for COVID-19: the role of nanotechnology in the treatment and diagnosis of COVID-19. Emergent Mater. https://doi.org/10.1007/s42247-021-00168-8

111. Shin MD, Shukla S, Chung YH, Beiss V, Chan SK, Ortega-Rivera O, Wirth DM, Chen A, Sack M, Pokorski JK, Steinmetz NF (2020) COVID-19 vaccine developmentand a potential nanomaterial path forward. Nat Nanotechnol 15(8):646-655

112. Milane L, Amiji M (2021) Clinical approval of nanotechnology-based SARS-CoV-2 mRNA vaccines: impact on translational nanomedicine. Drug Deliv Transl Res 11(4):1309-1315. https://doi.org/10.1007/ s13346-021-00911-y

113. Noor R (2021) Developmental status of the potential vaccines for the mitigation of the COVID-19 pandemic and a focus on the effectiveness of the Pfizer-BioNTech and moderna mRNA vaccines. Curr Clin Microbiol Rep 3:1-8. https://doi.org/10.1007/s40588-021-00162-y

114. Belete TM (2021) Review on up-to-date status of candidate vaccines for COVID-19 disease. Infect Drug Resist 14:151-161

115. Bobo D, Robinson KJ, Islam J, Thurecht KJ, Corrie SR (2016) Nanoparticle-based medicines: a review of FDA-approved materials and clinical trials to date. Pharm Res 33(10):2373-2387. https://doi.org/10.1007/ s11095-016-1958-5

\section{Publisher's Note}

Springer Nature remains neutral with regard to jurisdictional claims in published maps and institutional affiliations.

\section{Submit your manuscript to a SpringerOpen ${ }^{\circ}$ journal and benefit from:}

- Convenient online submission

- Rigorous peer review

- Open access: articles freely available online

- High visibility within the field

- Retaining the copyright to your article

Submit your next manuscript at $\boldsymbol{\nabla}$ springeropen.com 